\title{
POINTWISE APPROXIMATION BY BÉZIER VARIANT OF AN OPERATOR BASED ON LAGUERRE POLYNOMIALS
}

\author{
Sheetal Deshwal, Ana Maria Acu and P. N. Agrawal
}

\begin{abstract}
In 2013, Öksüzer et al. [Math. Meth. Appl. Sci., Doi: 10.1002/mma.3705] defined the Bézier variant of an operator involving Laguerre polynomials of degree $\mathrm{k}$ and studied the rate of convergence of these operators. In the present paper, our aim is to study the degree of approximation of these operators by means of the first order Ditzian-Totik modulus of smoothness and also obtain a quantitative Voronovskaja type theorem and the error in the approximation of functions having derivatives of bounded variation.
\end{abstract}

Mathematics subject classification (2010): 41A36, 41A25.

Keywords and phrases: Laguerre polynomials, Bézier variant of an operator, modulus of smoothness, Voronovskaja type theorem.

\section{REFERENCES}

[1] T. ACAR, Asymptotic formulas for generalized Szász-Mirakyan operators, Appl. Math. Comput. (2015), 263, 233-239.

[2] T. ACAR, Quantitative q-Voronovskaya and q-Grüss-Voronovskaya-type results for q-Szász Operators, Georgian Math. J. (2016), 23 (4), 459-468.

[3] T. ACAR, A. ARAL AND I. RAŞA, Modified Bernstein-Durrmeyer operators, General Mathematics, (2014), 22 (1), 27-41.

[4] T. ACAR, A. ARAL AND I. RAŞA, The new forms of Voronovoskaya's theorem in weighted spaces, Positivity (2016), 20, 25-40.

[5] T. Acar, P. N. Agrawal and T. Neer, Bezier variant of the Bernstein-Durrmeyer type operators, Results Math (2017), doi:10.1007/s00025-016-0639-3.

[6] P. N. Agrawal, N. IsPiR AND A. KaJla, Approximation properties of Bezier-summation integral type operators based on Polya-Bernstein functions, Appl. Math. Comput. (2015), 259, 533-539.

[7] A. M. ACU, P. N. Agrawal and T. NeER, Approximation by modified Stancu operators, Numer. Funct. Anal. Optim. (2017), 38 (3), 279-292.

[8] A. KaJla, A. M. ACU And P. N. AgRawal, Baskakov-Szász-type operators based on inverse Pólyaeggenberger distribution, Ann. Funct. Anal. (2016), 8, 106-123.

[9] R. BOJANIC AND F. CHENG, Rate of Convergence of Bernstein polynomials for functions with derivatives of bounded variation, J. Math. Anal. Appl. (1989), 141, 136-151.

[10] R. BoJANiC AND F. CHENG, Rate of convergence of Hermite-Fejer polynomials for functions with derivatives of bounded variation, Acta Math. Hungar. (1992), 59, 91-102.

[11] E. W. Cheney and A. Sharma, Bernstein power series, Canad. J. Math. (1964), 16, 241-252.

[12] Z. Ditzian And V. Totik, Moduli of Smoothness, Springer, New York, (1987).

[13] Z. FinTA, Remark on Voronovskaja theorem for q-Bernstein operators, Stud. Univ. Babeş-Bolyai Math. 56 (2011), 335-339.

[14] V. Gupta, U. ABEL AND M. IVAn, Rate of convergence of Beta operators of second kind for functions with derivatives of bounded variation, Internal. J. Math. Math. Sci. (2005), 23, 3827-3833.

[15] V. Gupta, V. VASishtha AND M. K. GuPTA, Rate of convergence of summation integral type operators with derivatives of bounded variation, J. Inequal. Pure Appl. Math. (2003), 4 (2), Article 34.

[16] W. Meyer-König AND K. ZEller, Bernsteinsche potenzreihen, Studia Mathematica, (1960), 19, 89-94. 
[17] T. NeER, A. M. ACU AND P. N. AgRAWAL, Bézier variant of genuine-Durrmeyer type operators based on Pólya distribution, Carpathian J. Math. 33 (2017), no. 1, 73-86.

[18] Ö. ÖKSÜZER, H. KARSLI AND F. T. Yesildal, Rate of convergence of the Bézier variant of an operator involving Laguerre polynomials, Math. Meth. Appl. Sci., doi:10.1002/mma. 3705.

[19] Ö. ÖKSÜZER, H. KARSLI AND F. T. YESILDAL, Convergence rate of Bézier variant of an operator involving Laguerre polynomials of degree $n$, AIP Conference Proceeding (2013), 1558, 1160-1163.

[20] G. Szegö, Orthogonal polynomials, Am. Math. Soc. Colloquium Publications 23, rev. ed. (1959). 